\title{
Heliox Adjunct Therapy for Neonates With Congenital Diaphragmatic Hernia
}

\author{
Audra C Wise MD, Mallory A Boutin MPH, Ellen M Knodel RRT RRT-NPS, \\ James A Proudfoot MSc, Brian P Lane MD, Marva L Evans MD, Denise M Suttner MD, \\ and Amy L Kimball MD
}

\begin{abstract}
BACKGROUND: Congenital diaphragmatic hernia remains a complex disease with significant morbidity and mortality. Hypercarbia is a common derangement in this population, which often requires escalating ventilator support. By decreasing airway turbulence and enhancing $\mathrm{CO}_{2}$ removal, inhaled helium-oxygen mixture (heliox) has the potential to improve ventilation and thereby decrease ventilator support and its associated lung injury. METHODS: Retrospective cohort review of all neonates with congenital diaphragmatic hernia treated at Rady Children's Hospital San Diego during 2011-2015. Clinical characteristics were compared between the infants who were treated with heliox and those who did not receive this intervention. To analyze the effect of heliox in the subgroup that received this treatment, ventilator settings and arterial blood gas values were compared before and after starting heliox by using paired $t$ tests. RESULTS: During the study period, 45 neonates with congenital diaphragmatic hernia were admitted to our neonatal ICU, 28 received heliox, and 27 were analyzed. During heliox treatment, $\mathrm{P}_{\mathrm{aCO}}$ levels decreased from 68 to $49 \mathrm{~mm} \mathrm{Hg}(P<.001)$, amplitude decreased from 33 to $23 \mathrm{~cm} \mathrm{H} \mathrm{H}_{2} \mathrm{O}(P<.001)$, ventilator frequency decreased from 28 to 23 breaths/min $(P=.02), \mathrm{F}_{\mathrm{IO}_{2}}$ decreased from 0.52 to $0.40(P<.01)$, and $\mathrm{pH}$ increased from 7.3 to $7.4(P<.001)$. CONCLUSIONS: The addition of heliox to the standard practice of permissive hypercapnia facilitated improvement in gas exchange, which allowed a decrease in ventilator settings and oxygen exposure, both of which are known to contribute to lung injury in this population. A prospective trial is needed to more clearly define the acute and longterm impacts of this treatment. Key words: congenital diaphragmatic hernia $(\mathrm{CDH})$; heliox; pulmonary hypoplasia; ventilation. [Respir Care 2018;63(9):1147-1153. (C) 2018 Daedalus Enterprises]
\end{abstract}

\section{Introduction}

Congenital diaphragmatic hernia is a complex disease with unique pathophysiology. Clinical outcomes vary and

Dr Wise, Ms Boutin, Ms Knodel, Dr Lane, Dr Evans, Dr Suttner, Dr Kimball are affiliated with Division of Neonatology, Rady Children's Hospital San Diego, University of California San Diego, San Diego, California. Mr Proudfoot is affiliated with Clinical and Translational Research Institute, University of California San Diego, San Diego, California.

Partially supported by the National Institutes of Health, grant UL1TR000100 of Clinical and Translational Science Awards (CTSA) funding before August 13, 2015, and grant UL1TR001442 of CTSA funding beginning August 13, 2015, and beyond. The content is solely the responsibility of the authors and does not necessarily represent the official views of the National Institutes of Health. are determined largely by the degree of lung hypoplasia and the severity of pulmonary hypertension. ${ }^{1}$ Effective treatment strategies used to manage babies with congenital diaphragmatic hernia have been largely unchanged over the past 20 years. The cornerstone of today's management was heralded in the late 1990s, with strong evidence that discouraged hyperventilation and alkalization, and that promoted gentler approaches to ventilation..$^{2-4}$ This change in management set a new benchmark in survival reported by Kays in 1999, at $70-90 \%$, which remains the standard

\footnotetext{
Dr Wise presented a version of this paper at the EuroELSO 2014, held May 22-24, 2014, in Paris, France. Dr Wise presented short oral presentations at the CDH Workshop 2015, held September 15, 2015, in Toronto, Ontario, Canada; at the CDH International Workshop 2017, held November, 14-16, 2017, Liverpool, England.
} 
today. ${ }^{4-6}$ However, these improved outcomes belie a subset of patients with congenital diaphragmatic hernia who continue to vex clinicians. Patients in this group tend to have larger hernias, frequently do not respond to standard therapies, and, therefore, continue to have a mortality rate near 50\%. ${ }^{5,7-10}$ New treatment strategies are needed to improve outcomes and reduce the complications still present in these patients.

Heliox, an inhaled helium-oxygen mixture, has a lower gas density than traditional air, a nitrogen-oxygen mixture, and results in decreased turbulence and increased laminar flow. These properties, along with a higher $\mathrm{CO}_{2}$ diffusion coefficient, improve lung function by enhancing gas exchange in distal airways and alveoli. ${ }^{11-13} \mathrm{CO}_{2}$ diffuses 4 times faster with heliox compared with the standard nitrogen-oxygen mixture. ${ }^{13}$ Heliox also decreases the work of breathing by decreasing the inspiratory pressure required for a given gas flow. The effort required to move a volume of gas to the alveolus is decreased by up to one third when breathing helium. Clinically, heliox administration has been shown to improve pulmonary mechanics in a wide variety of respiratory conditions that affect all ages, from preterm infants to adults. ${ }^{12-23}$ Helium is an inert gas, like nitrogen, and has no biologic activity. However, with any change in the mixture of inspired gases, there is a risk of inadvertent reduction in oxygen concentration as well as the risks associated with modification of commercially available devices to function with heliox. ${ }^{24}$

The unique pathophysiology caused by the congenital diaphragmatic hernia malformation is characterized by abnormal lung parenchyma, in addition to abnormal airway formation and vascular development in both the ipsilateral and contralateral lungs. ${ }^{25}$ Due to this abnormal morphology, the lungs of patients with congenital diaphragmatic hernia may be particularly sensitive to ventilation and oxidative injury. 4,26,27 Hypercarbia is a common clinical derangement in this population, which often requires escalating ventilator support. By improving ventilation with decreased airway turbulence and enhanced $\mathrm{CO}_{2}$ removal, heliox may allow for lower ventilator settings and less barotrauma, thereby decreasing both acute and chronic pulmonary morbidity. In addition, the lower $\mathrm{P}_{\mathrm{aCO}}$ levels and increased $\mathrm{pH}$ may further reduce pulmonary hypertension and improve oxygen delivery without the need for increased ventilator support or $\mathrm{F}_{\mathrm{IO}_{2}}$.

\section{The authors have disclosed no conflicts of interest.}

Correspondence: Audra C Wise MD, Rady Children's Hospital, 3020 Children’s Way, MC 5008, San Diego, CA 92123. E-mail: acwise@ucsd.edu, awise@rchsd.org.

DOI: $10.4187 /$ respcare.06079

\section{QUICK LOOK}

\section{Current knowledge}

Congenital diaphragmatic hernia remains a complex disease with significant morbidity and mortality. Heliox is a low-density gas mixture that decreases airway turbulence and enhances $\mathrm{CO}_{2}$ removal. Mixtures of 50-60\% heliox have been shown to improve gas exchange in a number of respiratory conditions. Heliox use has not been reported in the congenital diaphragmatic hernia population.

\section{What this paper contributes to our knowledge}

The addition of heliox to the standard practice of permissive hypercapnia for subjects with congenital diaphragmatic hernia facilitated improvement in gas exchange, which allowed a decrease in ventilator settings and oxygen exposure. Our experience with heliox indicates a larger therapeutic window than previously reported, with evidence of improved ventilation at levels as low as $10 \%$ heliox.

\section{Methods}

A retrospective cohort study was conducted for all newborns with congenital diaphragmatic hernia admitted to the Rady Children's Hospital San Diego Neonatal Intensive Care Unit from January 2011 to December 2015. All patients with congenital diaphragmatic hernia admitted during the study period were included. This retrospective cohort review was approved by the University of California San Diego Institutional Review Board.

The first aim of this study was to characterize the differences between the subjects who received heliox and those who did not. The second aim was to determine whether the addition of heliox was associated with improved parameters of ventilation. $\mathrm{P}_{\mathrm{aCO}_{2}}$ levels and ventilator settings were chosen as markers of ventilation. The subject characteristics and hospital outcomes were extracted from the medical record. The heliox and non-heliox groups were compared by birth weight, gestational age, sidedness of congenital diaphragmatic hernia, time of repair, use of inhaled nitric oxide, pulmonary hypertension by cardiac echocardiography, extracorporeal membrane oxygenation use, death, age at death, and congenital diaphragmatic hernia defect type.

To analyze the effect of heliox in the subgroup that received it, blood gas values and associated ventilator settings ( $\mathrm{pH}, \mathrm{P}_{\mathrm{aCO}}$, oscillator amplitude, conventional ventilator frequency $\mathrm{F}_{\mathrm{IO}_{2}}$, and mean airway pressure) were evaluated at specified intervals over the first $24 \mathrm{~h}$ of heliox 
exposure. Each subject served as his or her own control. The time intervals for analysis were the following: preheliox (control) compared with post-heliox initiation at 1-2 h, $6 \mathrm{~h}, 12 \mathrm{~h}$, and $24 \mathrm{~h}$. Heliox concentration at initiation was determined by the $\mathrm{F}_{\mathrm{IO}_{2}}$ requirement at that time (ie, helium $30 \%$ if oxygen was $70 \%$ ). Heliox was initiated at the discretion of the neonatologist. Study subjects who had multiple heliox exposures during their hospitalization had each exposure analyzed separately. A heliox exposure was excluded from analysis if the therapy was not maintained for a continuous $24 \mathrm{~h}$ or if there were an inadequate number of arterial blood gas results.

Rady Children's Hospital San Diego is the regional referral center for pediatric surgery and extracorporeal membrane oxygenation. During the study period, these subjects were cared for by a consistent group of neonatologists, with practices that are in line with national standards for congenital diaphragmatic hernia ventilator management, including the following: goal $\mathrm{pH}$ of 7.3-7.4, $\mathrm{P}_{\mathrm{aCO}_{2}}$ of 50-65 $\mathrm{mm} \mathrm{Hg}$, and pre-ductal pulse oximetry saturation of $>88 \%$. In our practice, general indications for heliox use include respiratory acidosis and escalating ventilator settings to maintain goal $\mathrm{P}_{\mathrm{aCO}}$.

\section{Statistical Analysis}

The Fisher exact test and a 2-sample $t$ test were used to compare categorical and continuous variables, respectively, between the heliox and non-heliox groups. For the heliox analysis, a paired $t$ test was used to determine if there were any pairwise differences from the pre-heliox time point to any of the other time points. Statistical tests were 2-tailed, and $P<.05$ was considered significant.

\section{Results}

During the study period, 45 infants were admitted to the neonatal ICU at Rady Children's Hospital San Diego with the diagnosis of congenital diaphragmatic hernia. Of these, 41 underwent surgical repair. Four died before repair: 2 due to cardiac comorbidities and 2 who experienced early bleeding complications on extracorporeal membrane oxygenation. A total of 28 subjects received treatment with heliox, and 27 subjects were included in the analysis. One subject was excluded due to inadequate number of blood gas results. No subjects required early discontinuation of heliox due to intolerance.

Subject characteristics are displayed in Table 1. There were no statistically significant differences in birth weight, gestational age, sidedness of congenital diaphragmatic hernia, extracorporeal membrane oxygenation use, or death between infants who received heliox and those who did not. However, the 2 groups differed in a few key areas. The subjects who received heliox underwent repair of their hernias later, at an average of $11 \mathrm{~d}$ versus $6 \mathrm{~d}$ for the non-heliox group $(P=.01)$. In addition, there were more subjects with moderate-severe and severe pulmonary hypertension by echocardiography in the heliox group $(P=.02)$. Consequently, this group also had increased inhaled nitric oxide exposure $(P=.02)$. Congenital diaphragmatic hernia defect types were defined by International Consensus Criteria. ${ }^{28}$ In our cohort, type B comprised the largest portion in the non-heliox group at 50\%, and type $\mathrm{C}$ comprised the largest portion of the heliox group at just over 59\%. In addition, the heliox group had the majority of the right-sided defects ( 9 of the 12 total), although this difference did not reach statistical significance. Despite this difference in clinical severity, the survival to discharge was $75 \%$ for the heliox group and $76 \%$ for the non-heliox group $(P>.99)$. In addition, there was a wider range in the time of death for the subjects who received heliox treatment, between 14 and $309 \mathrm{~d}$ compared with 2 and $18 \mathrm{~d}$ for the non-heliox group.

For the heliox analysis, each exposure was analyzed as a separate event and each subject served as his or her own control. Thirteen infants had more than one exposure to this therapy during their hospital course. From the 27 subjects treated with heliox, there were a total of 41 episodes of heliox use: 15 preoperative for congenital diaphragmatic hernia repair, 8 perioperative (started within $24 \mathrm{~h}$ pre/post-surgical repair), and 18 postoperative. High-frequency ventilation was used in 28 of the heliox exposures, and 13 heliox episodes occurred on conventional ventilation. Helium concentration used at initiation was determined by the oxygen requirement of the subject at that time and ranged from $10-70 \%$ (90-30\% oxygen). Ventilator settings and $\mathrm{P}_{\mathrm{aCO}}$ were chosen as markers of ventilation.

As depicted in Table 2, there was a statistically significant decrease in $\mathrm{P}_{\mathrm{aCO}_{2}}$ levels from the pre-heliox baseline to the first blood gas post-heliox treatment and the decrease was maintained during the 24-h analysis window. Levels of $\mathrm{P}_{\mathrm{aCO}}$ decreased from a mean of $68 \mathrm{~mm} \mathrm{Hg}$ pre-heliox to $48 \mathrm{~mm} \mathrm{Hg}$ at $1-2 \mathrm{~h}$ post-heliox treatment $(P<.001)$; the nadir was a mean of $46 \mathrm{~mm} \mathrm{Hg}$ at $6 \mathrm{~h}$ $(P<.001)$, and the $\mathrm{P}_{\mathrm{aCO}_{2}}$ stabilized between 12 and $24 \mathrm{~h}$ of exposure, with means of 48 and $49 \mathrm{~mm} \mathrm{Hg}(P<.001)$. There was a significant increase in $\mathrm{pH}$ during this time period from 7.3 to $7.4(P<.001)$, which corresponded to the change in $\mathrm{P}_{\mathrm{aCO}}$.

In addition, ventilator settings decreased during heliox treatment for both conventional and oscillator modes (Table 2). For amplitude, this was statistically significant for all time points. Before heliox treatment, the baseline mean oscillator amplitude was $33 \mathrm{~cm} \mathrm{H}_{2} \mathrm{O}$. The nadir amplitude was reached at $24 \mathrm{~h}$, with a mean of $23 \mathrm{~cm} \mathrm{H}_{2} \mathrm{O}(P<.001)$. 


\section{Heliox Adjunct Therapy for NeONATes}

Table 1. Subject Characteristics

\begin{tabular}{|c|c|c|c|c|}
\hline \multirow{2}{*}{ Characteristic } & \multicolumn{4}{|c|}{ Heliox } \\
\hline & No $(n=17)$ & Yes $(n=28)$ & Overall $(N=45)$ & $P$ \\
\hline Birth weight, g (range) & $2,866(1,015-4,309)$ & $3,003(1,380-3785)$ & $2,949(1,015-4,309)$ & .57 \\
\hline Gestational age, wk (range) & $37.7(29.0-41.4)$ & $37.9(31.3-41.4)$ & $37.8(29.0-41.4)$ & .86 \\
\hline \multicolumn{5}{|l|}{ Diagnosis, $n(\%)$} \\
\hline Bilateral & $0(0)$ & $1(4)$ & $1(2)$ & .47 \\
\hline Left & $14(82)$ & $18(64)$ & $32(71)$ & \\
\hline Right & $3(18)$ & $9(32)$ & $12(27)$ & \\
\hline Age at time of repair, $\mathrm{d}$ (range)* & $6(1-18)$ & $11(3-27)$ & NA & .01 \\
\hline \multicolumn{5}{|l|}{ Pulmonary hypertension by echocardiography, $n(\%) \dagger$} \\
\hline Mild-moderate & $5(29)$ & $0(0)$ & $5(11)$ & .02 \\
\hline Moderate & $5(29)$ & $8(29)$ & $13(29)$ & \\
\hline Moderate-severe & $1(6)$ & $3(11)$ & $4(9)$ & \\
\hline Severe & $6(35)$ & $17(61)$ & $23(51)$ & \\
\hline INO, $n(\%)$ & $10(59)$ & $26(93)$ & $36(80)$ & .02 \\
\hline \multicolumn{5}{|l|}{$\mathrm{ECMO}, n(\%)$} \\
\hline No & $14(82)$ & $22(79)$ & $36(80)$ & $>.99$ \\
\hline Yes & $3(18)$ & $6(21)$ & $9(20)$ & \\
\hline \multicolumn{5}{|l|}{ Death before discharge, $n(\%)$} \\
\hline No & $13(76)$ & $21(75)$ & $34(76)$ & $>.99$ \\
\hline Yes & $4(24)$ & $7(25)$ & $11(24)$ & \\
\hline Age at death, d (range) & $9(2-18)$ & 137 (14-309) & NA & .064 \\
\hline Congenital diaphragmatic hernia defect type, $n(\%) \ddagger$ & & & & .08 \\
\hline A & $1(6)$ & $2(7)$ & $3(7)$ & \\
\hline B & $7(41)$ & $5(18)$ & $12(27)$ & \\
\hline $\mathrm{C}$ & $3(18)$ & $16(57)$ & $19(42)$ & \\
\hline $\mathrm{D}$ & $3(18)$ & $4(14)$ & $7(16)$ & \\
\hline Unknown§ & $3(18)$ & $1(4)$ & $4(9)$ & \\
\hline \multicolumn{5}{|c|}{$\begin{array}{l}\text { * Three subjects in the no-heliox group unrepaired, } 1 \text { subject in the heliox group unrepaired. } \\
\text { † Classification of pulmonary hypertension obtained from cardiac echocardiography performed within the first } 72 \mathrm{~h} \text { of life. } \\
\text { ₹ Definitions per International Consensus Criteria: Type A defects are surrounded entirely by muscle; type B defects are considered small, with }<50 \% \text { of the chest wall lacking diaphragm tissue; } \\
\text { type C defects are large, with }>50 \% \text { of the chest wall devoid of diaphragm tissue; and type D defects describe complete or nearly complete absence of the diaphragm (from Reference } 28 \text { ). } \\
\text { The subjects were unable to have surgery due to clinical instability or compassionate care. } \\
\text { Heliox = helium-oxygen mixture } \\
\text { INO = inhaled nitric oxide } \\
\text { ECMO = extracorporeal membrane oxygenation }\end{array}$} \\
\hline
\end{tabular}

Table 2. Paired $t$ Test Analysis: Changes Over Time During Heliox Treatment

\begin{tabular}{|c|c|c|c|c|c|c|c|c|c|}
\hline \multirow{3}{*}{ Analysis } & \multirow{3}{*}{$\begin{array}{c}\text { Pre-Heliox } \\
\text { Treatment } \pm \text { SD }\end{array}$} & \multicolumn{8}{|c|}{ Post-Heliox Treatment } \\
\hline & & \multicolumn{2}{|c|}{$1-2 \mathrm{~h}$} & \multicolumn{2}{|l|}{$6 \mathrm{~h}$} & \multicolumn{2}{|c|}{$12 \mathrm{~h}$} & \multicolumn{2}{|c|}{$24 \mathrm{~h}$} \\
\hline & & $\pm \mathrm{SD}$ & $P$ & $\pm \mathrm{SD}$ & $P$ & $\pm \mathrm{SD}$ & $P$ & $\pm \mathrm{SD}$ & $P$ \\
\hline $\mathrm{P}_{\mathrm{aCO}_{2}}, \mathrm{~mm} \mathrm{Hg}$ & $67.5 \pm 13.6$ & $47.5 \pm 11.3$ & $<.001$ & $46.0 \pm 8.7$ & $<.001$ & $48.3 \pm 8.8$ & $<.001$ & $49.2 \pm 8.0$ & $<.001$ \\
\hline $\mathrm{pH}$ & $7.3 \pm 0.1$ & $7.4 \pm 0.1$ & $<.001$ & $7.4 \pm 0.1$ & $<.001$ & $7.4 \pm 0.1$ & $<.001$ & $7.4 \pm 0.1$ & $<.001$ \\
\hline Ventilator amplitude, $\mathrm{cm} \mathrm{H}_{2} \mathrm{O}^{*}$ & $33.2 \pm 6.1$ & $31.6 \pm 6.4$ & .02 & $27.3 \pm 6.2$ & $<.001$ & $24.5 \pm 5.9$ & $<.001$ & $22.8 \pm 6.0$ & $<.001$ \\
\hline Ventilator frequency, breaths $/ \min \dagger$ & $27.9 \pm 6.8$ & $28.0 \pm 7.2$ & .78 & $24.5 \pm 7.5$ & .08 & $23.3 \pm 6.9$ & .030 & $22.7 \pm 6.2$ & .02 \\
\hline $\mathrm{F}_{\mathrm{IO}_{2}}$ & $0.52 \pm 0.20$ & $0.45 \pm 0.14$ & $<.001$ & $0.42 \pm 0.12$ & $<.001$ & $0.41 \pm 0.13$ & $<.001$ & $0.40 \pm 0.11$ & $<.001$ \\
\hline
\end{tabular}




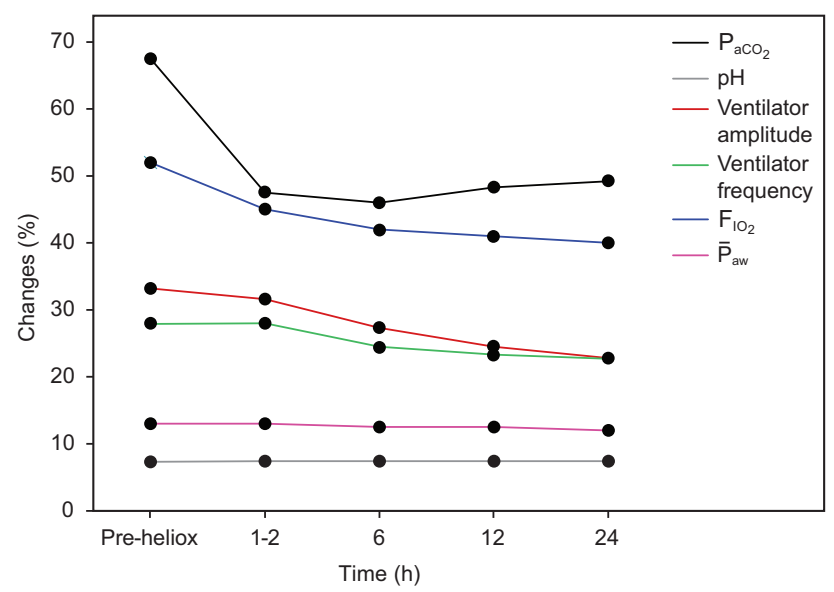

Fig. 1. Composite changes over time during heliox (inhaled helium-oxygen mixture) treatment. $\mathrm{F}_{\mathrm{IO}_{2}}$ is displayed as percentage for ease of comparison. $\overline{\mathrm{P}}_{\mathrm{aw}}=$ mean airway pressure.

For conventional ventilation, the effect became significant by $12 \mathrm{~h}$ after initiation of heliox. Before heliox treatment, the baseline mean ventilator frequency for those on conventional ventilation was 28 breaths $/ \mathrm{min}$. The rate decreased to 23 breaths/min at 12 and $24 \mathrm{~h}(P=.030$ and .02 , respectively). In addition, there was a small but significant decrease in $\mathrm{F}_{\mathrm{IO}_{2}}$, from 0.52 to $0.40(P<.001)$. The mean airway pressure was unchanged throughout the $24 \mathrm{~h}$ of heliox treatment. Composite changes over time are shown in Figure 1.

\section{Discussion}

In this cohort review, we found that the adjunctive use of heliox corresponded with improved gas exchange and reduced ventilator support in patients with congenital diaphragmatic hernia. Effects were maintained at $24 \mathrm{~h}$ of heliox administration. The decrease in ventilator support over the first $24 \mathrm{~h}$ seemed to be tolerated as evidenced by the stable trend of $\mathrm{P}_{\mathrm{aCO}_{2}}$ seen at 12 and $24 \mathrm{~h}$. This supports a positive effect of heliox while on ventilation in our cohort.

We chose to focus on the initial $24 \mathrm{~h}$ of exposure given the acute effect of heliox and the limitations of a retrospective analysis. We hypothesized that this interval would allow enough time to demonstrate the clinical effects of heliox, while decreasing exposure to possible confounding variables that would increase over longer study periods. The acute effect of heliox on gas exchange is demonstrated by the significant change in $\mathrm{P}_{\mathrm{aCO}_{2}}$ shown within 1-2 $\mathrm{h}$ after exposure (this was the first arterial blood gas drawn after initiation). This was the most dramatic change in $\mathrm{P}_{\mathrm{aCO}_{2}}$ during the study time period and could only be explained by the addition of heliox because the ventilator settings were largely unchanged during this short time interval. This acute improvement in ventilation was not transitory but rather sustained over the $24-\mathrm{h}$ period. The stable trend of $\mathrm{P}_{\mathrm{aCO}_{2}}$ seen at the 12- and 24-h intervals was continued, even while ventilator support was decreasing. Although our analysis was limited to $24 \mathrm{~h}$, it is our experience that heliox continues to improve airway dynamics beyond $24 \mathrm{~h}$ of use. Theoretically, there is no reason why this effect would be limited to $24 \mathrm{~h}$.

The decrease in $\mathrm{F}_{\mathrm{IO}_{2}}$ over this study period was small but statistically significant. This amount of change may have uncertain clinical importance; however, it is important to note that the improvement occurred over a relatively short period and despite concurrent reductions in ventilator settings. This reduced oxygen requirement occurred without an increase in mean airway pressure. This effect is likely multifactorial. Improved laminar flow leads to better gas exchange in the distal airways, whereas lower $\mathrm{P}_{\mathrm{aCO}_{2}}$ and increased $\mathrm{pH}$ allow for vasodilatation, which improves pulmonary hypertension.

Although consensus from the literature indicates a minimum effective dose of 50-60\% helium, there may be a larger therapeutic window for heliox. ${ }^{29}$ Theoretically, there is no minimum concentration at which heliox should not provide some advantage because helium is lighter than nitrogen. ${ }^{13}$ Case reports ${ }^{12}$ and a small proof-of-concept study demonstrated clinical effect with concentrations down to $20-25 \%$ helium. ${ }^{29}$ In our study group, there was a wide range of helium concentrations used at initiation of treatment: $10-70 \%$. Of note, no patients had to be taken off heliox due to acute hypoxia after initiation. Heliox concentrations could not be analyzed separately due to our study size and heterogeneity. However, helium levels as low as $10 \%$ were still associated with a progressive improvement in ventilation. Thus, heliox is a potentially viable treatment, even for patients with congenital diaphragmatic hernia who have a very high oxygen requirement.

The heliox group was biased to include a greater amount of high risk subjects, which is evident in the severity of pulmonary hypertension by echocardiography, inhaled nitric oxide use, age at repair, and defect type. It is our experience that this population often has issues of hypercarbia, independent of oxygenation. Heliox is typically initiated in patients who are not responding to standard treatment or who are deteriorating from a ventilation standpoint. The mean starting $\mathrm{F}_{\mathrm{IO}_{2}}$ of 0.5 and the mean starting $\mathrm{P}_{\mathrm{aCO}_{2}}$ of $68 \mathrm{~mm} \mathrm{Hg}$ support this. Although the clinical severity differed between the group that received heliox and the group that did not, the requirement of extracorporeal membrane oxygenation and mortality rates were similar. In addition, the heliox group had a wider range in time of death. Due to the retrospective design of this study, these findings were limited to interpretation but were, at the very least, encouraging trends for this more severely affected congenital diaphragmatic hernia population. 


\section{Heliox Adjunct Therapy for NeONATES}

Given the limitations of a retrospective cohort review with multiple confounding variables, including varied start times (ie, pre-, peri-, and postoperative) and $\mathrm{F}_{\mathrm{IO}_{2}}$ requirements, we were not able to directly compare the heliox and non-heliox groups. We believed that the most rigorous way to assess the effect of heliox in this historical cohort was to use each individual as his or her own control. Thus, each episode occurred with the same confounding variables, which limited interpersonal variation. Most of the heliox episodes occurred in the first days of life or near the congenital diaphragmatic hernia repair, as expected, given that the respiratory status of these babies is quite tenuous during that time frame. Eight episodes occurred more than $14 \mathrm{~d}$ after congenital diaphragmatic hernia repair. These corresponded with acute deteriorations in respiratory status related primarily to infection or subsequent surgeries. Although these later exposures were not acutely related to the congenital diaphragmatic hernia itself, the underlying pathophysiology of the lung remained the same.

The initiation of heliox was clinically determined and varied in timing and duration. Therefore, it is unlikely that the changes in blood gas and ventilator data were simply due to natural history. The short study period and analysis of each individual exposure also diminished the likelihood that these results could be explained by any other intervention or change in clinical care. Concurrent therapies were administered regardless of heliox administration, including inhaled nitric oxide, steroids, and vasoactive medications.

Patients with congenital diaphragmatic hernia have multiple long-term issues, including chronic lung disease, feeding difficulty, and neurodevelopmental concerns. Recent data reconfirmed a connection between pulmonary status and developmental delay. ${ }^{30,31}$ Therapies that minimize the degree and duration of ventilator support would be expected to decrease respiratory morbidity and improve outcomes, both during the initial hospitalization and after discharge.

Improved understanding of the unique pathophysiology present in the patient with congenital diaphragmatic hernia, coupled with strategies to prevent ventilator-induced lung injury, has led to dramatic changes in how we treat these patients. The adoption of these therapies has resulted in significant improvement in their survival. In building on this knowledge, heliox offers a novel strategy to improve flow dynamics and gas exchange through abnormal airways with peripheral obstruction, which allows for lower ventilator settings. Heliox may also improve oxygen delivery due to laminar flow dynamics and may enhance pulmonary vasodilatation by minimizing hypercarbia and normalizing $\mathrm{pH}$. This effect could indirectly improve pulmonary hypertension without requiring higher ventilator settings or increasing oxygen exposure.
The limitations of this study included retrospective data collection and the lack of a formal protocol for heliox use, patient heterogeneity, variable timing and concentration of heliox therapy, and lack of a matched control group. Despite its limitations, this sort of retrospective analysis has been an important method for advancing care in this unique population.

\section{Conclusions}

At our institution, heliox has become an important adjunctive therapy in the clinical management of infants with congenital diaphragmatic hernia. The addition of heliox to the standard practice of gentle ventilation and permissive hypercapnia allows for further improvement in gas exchange and thus a decrease in ventilator support and oxygen exposure, which are known to contribute to lung injury in this population. A prospective trial is needed to more clearly define the acute and long-term impacts of this treatment.

\section{REFERENCES}

1. Thébaud B, Mercier JC, Dinh-Xuan AT. Congenital diaphragmatic hernia. A cause of persistent pulmonary hypertension of the newborn which lacks an effective therapy. Biol Neonate 1998;74(5):323-336.

2. Wung JT, James LS, Kilchevsky E, James E. Management of infants with severe respiratory failure and persistence of the fetal circulation, without hyperventilation. Pediatrics 1985;76(4):488-494.

3. Wung JT, Sahni R, Moffitt ST, Lipsitz E, Stolar CJ. Congenital diaphragmatic hernia: survival treated with very delayed surgery, spontaneous respiration, and no chest tube. J Pediatr Surg 1995; 30(3):406-409.

4. Kays DW, Langham MR Jr, Ledbetter DJ, Talbert JL. Detrimental effects of standard medical therapy in congenital diaphragmatic hernia. Ann Surg 1999;230(3):340-348; discussion 348-351.

5. Badillo A, Gingalewski C. Congenital diaphragmatic hernia: treatment and outcomes. Semin Perinatol 2014;38(2):92-96.

6. Wynn J, Krishnan U, Aspelund G, Zhang Y, Duong J, Stolar CJ, et al. Outcomes of congenital diaphragmatic hernia in the modern era of management. J Pediatr 2013;163(1):114-119.e1.

7. Hedrick HL, Danzer E, Merchant A, Bebbington MW, Zhao H, Flake AW, et al. Liver position and lung-to-head ratio for prediction of extracorporeal membrane oxygenation and survival in isolated left congenital diaphragmatic hernia. Am J Obstet Gynecol 2007;197(4): 422.e1-e4.

8. Brindle ME, Cook EF, Tibboel D, Lally PA, Lally KP; Congenital Diaphragmatic Hernia Study Group. A clinical prediction rule for the severity of congenital diaphragmatic hernias in newborns. Pediatrics 2014;134(2):e413-e419.

9. Congenital Diaphragmatic Hernia Study Group, Lally KP, Lally PA, Lasky RE, Tibboel D, Jaksic T, et al. Defect size determines survival in infants with congenital diaphragmatic hernia. Pediatrics 2007; 120(3):e651-e657.

10. Seetharamaiah R, Younger JG, Bartlett RH, Hirschl RB; Congenital Diaphragmatic Hernia Study Group. Factors associated with survival in infants with congenital diaphragmatic hernia requiring extracorporeal membrane oxygenation: a report from the Congenital Diaphragmatic Hernia Study Group. J Pediatr Surg 2009; 44(7):1315-1321. 


\section{Heliox Adjunct Therapy for NeONATes}

11. Frazier MD, Cheifetz IM. The role of heliox in paediatric respiratory disease. Paediatr Respir Rev 2010;11(1):46-53; quiz 53.

12. Winters JW, Willing MA, Sanfilippo D. Heliox improves ventilation during high-frequency oscillatory ventilation in pediatric patients. Pediatr Crit Care Med 2000;1(1):33-37.

13. Ho AM, Dion PW, Karmakar MK, Chung DC, Tay BA. Use of heliox in critical upper airway obstruction. Physical and physiologic considerations in choosing the optimal helium:oxygen mix. Resuscitation 2002;52(3):297-300.

14. Gentile MA. Inhaled medical gases: more to breathe than oxygen. Respir Care 2011;56(9):1341-1357; discussion 1357-1359.

15. Nawab US, Touch SM, Irwin-Sherman T, Blackson TJ, Greenspan JS, Zhu G, et al. Heliox attenuates lung inflammation and structural alterations in acute lung injury. Pediatr Pulmonol 2005; 40(6):524-532.

16. Szczapa T, Gadzinowski J. Use of heliox in the management of neonates with meconium aspiration syndrome. Neonatology 2011; 100(3):265-270

17. Migliori C, Gancia P, Garzoli E, Spinoni V, Chirico G. The effects of helium/oxygen mixture (heliox) before and after extubation in long-term mechanically ventilated very low birth weight infants. Pediatrics 2009;123(6):1524-1528.

18. Colnaghi M, Pierro M, Migliori C, Ciralli F, Matassa PG, Vendettuoli $\mathrm{V}$, et al. Nasal continuous positive airway pressure with heliox in preterm infants with respiratory distress syndrome. Pediatrics 2012; 129(2):e333-e338.

19. Dani C, Fontanelli G, Lori I, Favelli F, Poggi C. Heliox non-invasive ventilation for preventing extubation failure in preterm infants. $\mathrm{J}$ Matern Fetal Neonatal Med 2013;26(6):603-607.

20. Li X, Shen J, Zhao J, Tang S, Shi Y. Nasal intermittent positive pressure ventilation with heliox in premature infants with respiratory distress syndrome: a randomized controlled trial. Indian Pediatr 2014; 51(11):900-902.
21. Myers TR. Use of heliox in children. Respir Care 2006;51(6): 619-631.

22. Kass JE. Heliox redux. Chest 2003;123(3):673-676.

23. Chowdhury MM, McKenzie SA, Pearson CC, Carr S, Pao C, Shah AR, et al. Heliox therapy in bronchiolitis: phase III multicenter double-blind randomized controlled trial. Pediatrics 2013;131(4):661669.

24. Fink JB. Opportunities and risks of using heliox in your clinical practice. Respir Care 2006;51(6):651-660.

25. Areechon W, Reid L. Hypoplasia of lung with congenital diaphragmatic hernia. Br Med J 1963;1(5325):230-233.

26. Sakurai Y, Azarow K, Cutz E, Messineo A, Pearl R, Bohn D. Pulmonary barotrauma in congenital diaphragmatic hernia: a clinicopathological correlation. J Pediatr Surg 1999;34(12):1813-1817.

27. Rygl M, Rounova P, Sulc J, Slaby K, Stranak Z, Pycha K, et al. Abnormalities in pulmonary function in infants with high-risk congenital diaphragmatic hernia. Biomed Pap Med Fac Univ Palacky Olomouc Czech Repub 2015;159(3):497-502.

28. Lally KP, Lasky RE, Lally PA, Bagolan P, Davis CF, Frenckner BP, et al; Congenital Diaphragmatic Hernia Study Group. Standardized reporting for congenital diaphragmatic hernia-an international consensus. J Pediatr Surg 2013;48(12):2408-2415.

29. A Proof-Of-Concept Trial Of HELIOX With Different Fractions of Helium in Upper Airway Obstruction. B23 Outcomes, Health Services and Patient-Centered Research in the Intensive Care Unit. Am J Respir Crit Care Med in 2012;185:abstract 2561.

30. Cauley RP, Potanos K, Fullington N, Bairdain S, Sheils CA, Finkelstein JA, et al. Pulmonary support on day of life 30 is a strong predictor of increased 1 and 5-year morbidity in survivors of congenital diaphragmatic hernia. J Pediatr Surg 2015;50(5):849-855.

31. Bevilacqua F, Morini F, Zaccara A, Valfre L, Capolupo I, Bagolan P, Aite L. Neurodevelopmental outcome in congenital diaphragmatic hernia survivors: role of ventilatory time. J Pediatr Surg 2015;50(3): 394-398. 